\title{
Absolute Configuration of TPU-0043, a Pentaene Macrolide from Streptomyces sp.
}

\author{
Yasuhiro Igarashi, Yasuko In, Toshimasa Ishida, Tsuyoshi Fujita, Takashi Yamakawa, \\ Hiroyasu Onaka, Tamotsu Furumai
}

Received: June 1, 2005 / Accepted: July 16, 2005

(C) Japan Antibiotics Research Association

\begin{abstract}
An antifungal pentaene macrolide TPU-0043 was isolated from Streptomyces sp. TP-A0625. The absolute configuration of TPU-0043 was determined to be $2 R$-(n-butyl)-16-methyl-3S,5S,7S,9R,11R,13R,15S,26S, $27 R$-nonahydroxyoctacosa-16,18,20,22,24-pentaenoic acid, 27-lactone, by X-ray crystallography of its 13 - $p$-bromobenzenesulfonyl derivative.
\end{abstract}

Keywords polyene macrolide, antifungal antibiotic, Streptomyces

Polyene macrolides are an important class of antifungal antibiotics and most of them are produced by actinomycetes belonging to the genus Streptomyces. Polyene macrolides have attracted a great deal of interest from biologists and chemists by virtue of their potent antifungal activity and structural characteristics, along with the increasing incidence and severity of acute fungal infections. A variety of synthetic methodologies have been developed to chemically characterize this unique class of natural products $[1,2]$. Recently, biosynthesis of polyene macrolides has been intensively studied to generate improved fungicidal agents through genetic manipulations $[3,4]$. Although more than 200 polyene macrolides have been identified, the stereochemistry of many has not been fully characterized largely because of the signal overlapping in the NMR spectra due to the iterative

Y. Igarashi (Corresponding author), T. Yamakawa, H. Onaka, T. Furumai: Biotechnology Research Center, Toyama Prefectural University, 5180 Kurokawa, Kosugi, Toyama 939-0398, Japan, E-mail: yas@pu-toyama.ac.jp

Y. In, T. Ishida: Department of Physical Chemistry, Osaka structural motifs and structural complexity. Among the pentaene macrolides, the absolute configuration of pentamycin (=fungichromin) [5, 6] and filipin III [2] was determined by spectral comparison of the degradation products and partial synthesis. On the other hand, the absolute configuration of rotaxaticin [7] and amphotericin B [8] was confirmed by X-ray crystallography in combination with analysis of degradation products. We herein describe the assignment of the absolute configuration of a pentaene macrolide TPU-0043.

In the screening of antifungal antibiotics from microbial secondary metabolites, Streptomyces sp. TP-A0625 was found to produce a polyene macrolide containing a pentaene moiety (UV $\lambda_{\max } 322,338$ and $356 \mathrm{~nm}$ ). Strain TP-A0625 was isolated from a leaf of a perennial Parthenocissue tricuspidata [9] and identified as Streptomyces sp. on the basis of the taxonomic study. A loopful of a mature slant culture of strain TP-A0625 on Bennet's agar was inoculated into a 500-ml K-1 flask containing $100 \mathrm{ml}$ of the seed medium consisting of soluble starch $1 \%$, glucose $0.5 \%$, NZ-case $0.3 \%$, yeast extract $0.2 \%$, tryptone $0.5 \%, \mathrm{~K}_{2} \mathrm{HPO}_{4} 0.1 \%, \mathrm{MgSO}_{4} \cdot 7 \mathrm{H}_{2} \mathrm{O} 0.05 \%$, and $\mathrm{CaCO}_{3} 0.3 \%$ (pH 7.0). The flask was incubated at $30^{\circ} \mathrm{C}$ for 4 days on a rotary shaker $(200 \mathrm{rpm})$. Three-ml aliquots of the seed culture were transferred into one hundred 500 $\mathrm{ml} \mathrm{K}-1$ flasks each containing $100 \mathrm{ml}$ of the production medium consisting of glucose $0.5 \%$, glycerol $2 \%$, soluble starch 2\%, Pharmamedia (Trader's Protein) 1.5\%, yeast extract $0.3 \%, \mathrm{KH}_{2} \mathrm{PO}_{4} 2.18 \%, \mathrm{Na}_{2} \mathrm{HPO}_{4} 1.48 \%$, and HP-20
University of Pharmaceutical Sciences, 4-20-1 Nasahara, Takatsuki, Osaka 569-1041, Japan

T. Fujita: Suntory Institute for Bioorganic Research, 1-1-1 Wakayamadai, Shimamoto, Mishima, Osaka 618-8503, Japan 
Table 1 NMR data for TPU-0043 in $\mathrm{CD}_{3} \mathrm{OD}$

\begin{tabular}{|c|c|c|c|}
\hline No. & $\delta^{13} \mathrm{C}$ & $\delta^{1} \mathrm{H}$ (integral, mult., $J \mathrm{~Hz}$ ) & Position \\
\hline 1 & 11.37 & $1.77(3 \mathrm{H}, \mathrm{s})$ & 29 \\
\hline 2 & 14.24 & $0.90(3 \mathrm{H}, \mathrm{t}, 7.3)$ & $4^{\prime}$ \\
\hline 3 & 18.31 & $1.30(3 \mathrm{H}, \mathrm{d}, 6.1)$ & 28 \\
\hline 4 & 23.61 & $1.32(2 \mathrm{H})$ & $3^{\prime}$ \\
\hline 5 & 29.91 & $1.57(1 \mathrm{H}), 1.73(1 \mathrm{H})$ & $1^{\prime}$ \\
\hline 6 & 30.60 & $1.25 \sim 1.32(2 \mathrm{H})$ & $2^{\prime}$ \\
\hline 7 & 42.48 & $1.38(2 \mathrm{H})$ & \\
\hline 8 & 42.67 & $1.72(1 \mathrm{H}), 1.90(1 \mathrm{H})$ & \\
\hline 9 & 44.10 & $1.3 \sim 1.5(2 \mathrm{H})$ & $4,6,8,10$ \\
\hline 10 & 44.83 & $1.3 \sim 1.5(2 \mathrm{H})$ & 12,14 \\
\hline 11 & 45.04 & $1.45(1 \mathrm{H}), 1.75(1 \mathrm{H})$ & \\
\hline 12 & 45.14 & $1.3 \sim 1.5(2 \mathrm{H})$ & \\
\hline 13 & 54.27 & $2.31(1 \mathrm{H}, \mathrm{ddd}, 3.7,7.6,11.2)$ & 2 \\
\hline 14 & 67.45 & $3.30(1 \mathrm{H})$ & 13 \\
\hline 15 & 70.97 & & \\
\hline 16 & 73.14 & $3.95 \sim 4.01(3 \mathrm{H})$ & $5,7,26$ \\
\hline 17 & 73.30 & & \\
\hline 18 & 73.39 & $3.81(1 \mathrm{H}, \mathrm{dt}, 4.6,7.6)$ & 3 \\
\hline 19 & 73.57 & $395 \sim 401$ (2H) & 911 \\
\hline 20 & 74.12 & & \\
\hline 21 & 74.45 & $4.84(1 \mathrm{H}, \mathrm{m})$ & 27 \\
\hline 22 & 75.62 & $4.14(1 \mathrm{H}, \mathrm{dd}, 4.2,10.5)$ & 15 \\
\hline 23 & 128.06 & $6.06(1 \mathrm{H}, \mathrm{d}, 11.2)$ & 17 \\
\hline 24 & 129.56 & $6.50(1 \mathrm{H}, \mathrm{dd}, 11.2,13.9)$ & 18 \\
\hline 25 & 132.37 & & \\
\hline 26 & 133.65 & $628 \sim 642(4 \mathrm{H})$ & $19 \sim 24$ \\
\hline 27 & 134.16 & & \\
\hline 28 & 134.23 & & \\
\hline 29 & 134.44 & $5.91(1 \mathrm{H}, \mathrm{m})$ & 25 \\
\hline 30 & 134.59 & $628 \sim 642(2 \mathrm{H})$ & $19 \sim 24$ \\
\hline 31 & 134.71 & $6.28 \sim 6.42(2 \mathrm{H})$ & $19 \sim 24$ \\
\hline 32 & 140.58 & & 16 \\
\hline 33 & 175.39 & & 1 \\
\hline
\end{tabular}

Spectra were recorded at $400 \mathrm{MHz}$ for ${ }^{1} \mathrm{H}$ and $100 \mathrm{MHz}$ for ${ }^{13} \mathrm{C}$. Solvent peaks were used as a reference $\left(\delta_{H} 3.30 ; \delta_{C} 49.0\right)$.

resin (Mitsubishi Chemical) 1\% (pH 7). Fermentation was carried out at $30^{\circ} \mathrm{C}$ for 7 days on a rotary shaker $(200 \mathrm{rpm})$. The fermented whole broth (10 liters) was extracted with acetone (10 liters) and the supernatant was separated from mycelium by centrifugation. The supernatant was evaporated and the resultant aqueous solution was applied on a HP-20 resin column after the $\mathrm{pH}$ was adjusted to 7.0. The column was eluted with $80 \%$ acetone and the eluent was evaporated and extracted with 1-butanol. The organic layer was then concentrated in vacuo to give a crude extract $(3.65 \mathrm{~g})$. It was then washed with $30 \%$ aqueous methanol and TPU-0043 (2.09g) was obtained as a yellow crystalline solid. Recrystallization of TPU-0043 from $\mathrm{CH}_{2} \mathrm{Cl}_{2}-\mathrm{MeOH}$ afforded yellow fine needles with the melting point of $235 \sim 240^{\circ} \mathrm{C}$ (decomposition). The molecular formula was determined as $\mathrm{C}_{33} \mathrm{H}_{54} \mathrm{O}_{10}$ by the high-resolution FAB-MS (calcd. for $[\mathrm{M}+\mathrm{H}]^{+}$611.3795, found 611.3789). The FT-IR spectrum (KBr) exhibited bands which implied the presence of hydroxyl groups $\left(3375 \mathrm{~cm}^{-1}\right)$ and a lactone $\left(1710 \mathrm{~cm}^{-1}\right)$. The UV spectrum in $\mathrm{MeOH}$ showed absorption maxima (log $\varepsilon$ ) at 244 (3.73), 281 (sh, 3.91), 293 (sh, 4.06), 307 (4.29), 322 (4.50), 338 (4.63), and 356 (4.62) $\mathrm{nm}$, suggesting a pentaene group. Examination of the NMR and MS spectra indicated that TPU-0043 possesses the flat structure identical to chainin [10] from Chainia sp. and its stereoisomer, isochainin [11] from Streptomyces cellulosae. The structure of chainin has been determined by the MS analysis of its derivatives but the NMR and configurational assignments have not been made. The NMR data of TPU-0043 showed moderate similarity to that of isochainin but the two materials could not been conclusively distinguished. The specific rotation of chainin and isochainin is $[\alpha]_{\mathrm{D}}^{25}-112.2^{\circ}(c 0.16, \mathrm{MeOH})$ and $[\alpha]_{\mathrm{D}}^{25}$ $-24.4^{\circ}$ ( $\left.c 0.16, \mathrm{MeOH}\right)$, respectively, and that of TPU0043 was $[\alpha]_{\mathrm{D}}^{23}-114.9^{\circ}(c \quad 0.2, \mathrm{MeOH})$. This good accordance in specific rotation suggests that TPU-0043 is identical with chainin; however, the authentic sample of chainin was not available and there is no definitive evidence to address their identity. Therefore, we designate the pentaene macrolide from strain TP-A0625 as TPU-0043 in this article.

To determine the absolute configuration of TPU-0043 using X-ray diffraction, we examined derivatization with a bromine-containing group and found that the reaction with $p$-bromobenzenesulfonyl chloride in pyridine at $4^{\circ} \mathrm{C}$ gave a desired derivative. The reaction mixture was sequentially chromatographed on silica gel and ODS column to afford a derivative ( $13 \mathrm{mg}$ from $100 \mathrm{mg}$ of TPU-0043). The ESITOF-MS of the derivative gave an $[\mathrm{M}+\mathrm{Na}]^{+}$at $m / z 851.1$ (88\%), 852.1 (38\%), $853.1(100 \%)$ and $854.1(29 \%)$. This isotope peak distribution suggested the presence of a bromine atom in the molecule and thus the molecular formula was determined as $\mathrm{C}_{39} \mathrm{H}_{57} \mathrm{BrO}_{12} \mathrm{~S}$. The $p$ bromobenzenesulfonate of TPU-0043 was slowly crystallized from $\mathrm{MeOH}-\mathrm{EtOAc}$ to afford light yellow prisms. The prismatic crystal was analyzed by the X-ray diffraction and the absolute configuration of TPU-0043 was established as shown in Fig. 1. The $p$-bromobenzenesulfonyl group was substituted at the 13-OH group. Crystal data for 13-O- $p$-bromobenzenesulfonate of TPU0043 at $273 \mathrm{~K}: \mathrm{C}_{39} \mathrm{H}_{57} \mathrm{BrO}_{12} \mathrm{~S} \cdot \mathrm{CH}_{3} \mathrm{OH}, \quad M r=861.89$, orthorhonbic, space group $P 2_{1} 2_{1} 2_{1}, \quad a=9.589(1) \AA$, $b=17.720(3) \AA, c=26.227(4) \AA, V=4456.5(11) \AA^{3}, Z=4$, 


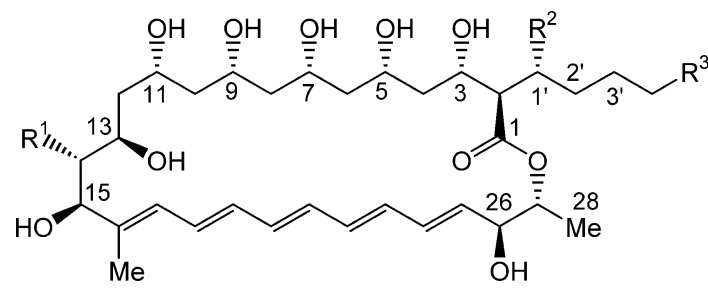

TPU-0043 $\left(R^{1}=R^{2}=R^{3}=H\right)$

Chainin, isochainin $\left(R^{1}=R^{2}=R^{3}=H\right.$; configuration unknown)

Pentamycin $\left(\mathrm{R}^{1}=\mathrm{R}^{2}=\mathrm{OH}, \mathrm{R}^{3}=\mathrm{CH}_{2} \mathrm{CH}_{3}\right)$

Filipin III $\left(\mathrm{R}^{1}=\mathrm{H}, \mathrm{R}^{2}=\mathrm{OH}, \mathrm{R}^{3}=\mathrm{CH}_{2} \mathrm{CH}_{3}\right)$

Fig. 1 Structure of TPU-0043 and related compounds.

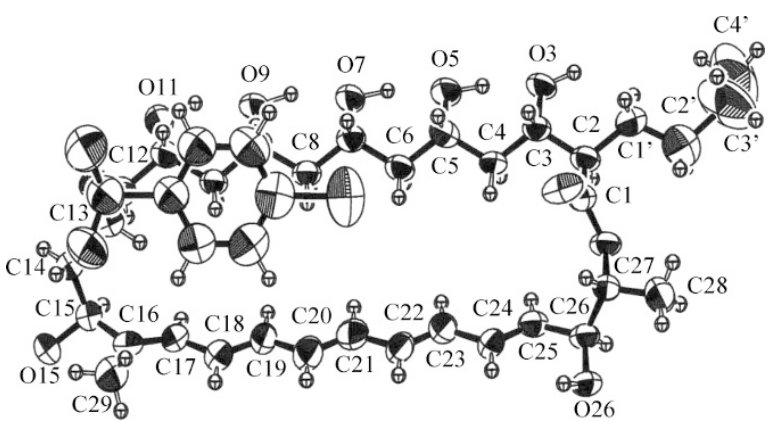

Fig. 2 Computer-generated ORTEP view drawing with atom labeling scheme and chemical drawing of 13-pbromobenzenesulfonate of TPU-0043.

$D_{\mathrm{c}}=1.285 \mathrm{~g} \mathrm{~cm}^{-3}, \quad \mu(\mathrm{Mo}-\mathrm{K} \alpha)=0.086 \mathrm{~mm}^{-1}, \quad F(000)=$ $1824, \chi$ parameter $=0.014, R=0.0614$. The supplementary crystallographic data (CCDC 204143) can be obtained free of charge via www.ccdc.cam.ac.uk/conts/retrieving.html (or from the Cambridge Crystallographic Data Centre, 12, Union Road, Cambridge CB21EZ, UK; fax: (+44) 1223 336-033; or deposit@ccdc.cam.ac.uk). The structural differences among TPU-0043, filipin III and pentamycin lie in the length of the side chain and the number of hydroxyl groups. The side chain at C-2 of TPU-0043 is 2 carbons shorter than that of filipin III and pentamycin. Filipin III has an additional hydroxyl group at $\mathrm{C}-1^{\prime}$ and pentamycin has two additional hydroxyl groups at $\mathrm{C}-1^{\prime}$ and $\mathrm{C}-14$.
Except for these differences, the three pentaene macrolides possess the same absolute configuration, suggesting their relevancy in biogenesis.

\section{References}

1. Evans DA, Connell BT. Synthesis of the antifungal macrolide antibiotic (+)-roxaticin. J Am Chem Soc 125: 10899-10905 (2003)

2. Richardson TI, Rychnovsky SD. Filipin III: Configuration assignment and confirmation by synthetic correlation. J Org Chem 61: 4219-4231 (1996)

3. Aparicio JF, Mendes MV, Anton N, Recio E, Martin JF. Polyene macrolide antibiotic biosynthesis. Curr Med Chem 11: 1645-1656 (2004)

4. Aparicio JF, Caffrey P, Gil JA, Zotchev SB. Polyene antibiotic biosynthesis gene clusters. Appl Microbiol Biotechnol 61: 179-188 (2003)

5. Oishi T. Studies directed towards the stereoselective synthesis of polyene macrolide antibiotics. Pure \& Appl Chem 61: 427-430 (1989)

6. Matsumoto K, Shimagaki M, Nakata T, Oishi T. Synthesis of acyclic polyol derivatives via enzyme-mediated aldol reaction. Tetrahedron Lett 34: 4935-4938 (1993)

7. Maehr H, Yang R, Hong LN, Liu CM, Hatada MH, Todaro LJ. Mirobial products. 9. Rotaxaticin, a new oxo pentaene antibiotic. J Org Chem 54: 3816-3819 (1989)

8. Mechlinski W, Schaffner CP, Ganis P, Avitabile G. Structure and absolute configuration of the polyene macrolide antibiotic amphotericin B. Tetrahedron Lett 3873-3876 (1970)

9. Igarashi Y, Iida T, Sasaki T, Saito N, Yoshida R, Furumai T. Isolation of actinomycetes from live plants and evaluation of their antiphytopathogenic activity of their metabolites. Actinomycetol 16: 9-13 (2002)

10. Pandy RC, Narasimhachari N, Rinehart KL Jr, Millington DS. Polyene antibiotics. IV. Structure of chainin. J Am Chem Soc 94: 4306-4310 (1972)

11. Li Z, Rawlings BJ, Harrison PH, Vederas JC. Production of new polyene antibiotics by Streptomyces cellulosae after addition of ethyl (Z)-16-phenylhexadec-9-enoate. J Antibiot 42: 577-584 (1989) 